\title{
Editorial
}

\section{Time, this month, for a little navel-gazing}

It starts with a couple of short pieces on data quality - the issues and some tentative solutions. I'm sure I've banged on about this before. I make no apology for doing so again.

In the last few months, wearing my other 'civilian' hat, I have worked on three projects that have had to be cancelled for reasons associated with data. Or, to be precise, poor data. There was the predictive modelling project, which foundered when it became clear that the IT department had not been updating the marketing system fully or accurately. Then there is the multi-million pound CRM system - going nowhere because the processes to check and enhance data are not in place. And, finally, there is the pan-European business that wants a new database, yet can't implement one because of the standard of its data.

There are many reasons for this. Not least is the fact that in most organisations, data has no true senior level champion. It is the bit that everyone assumes will be sorted out by everyone else. The bit that happens when the 'important' people leave the room.

I suppose I should be grateful. After all, it keeps me gainfully employed. I can firmly predict that in ten years time, when technology has moved on several light years beyond where we are now and the whole world is enthusing about the merits of the latest Linux CRM system - there will still be plenty of work to do on the data front.

Much as I am an enthusiast for sorting out data issues, the navel gazing goes a fair way beyond that. This issue contains a couple of practice papers which focus on data. More to the point, they are papers from suppliers with a story to tell.

On a good day, I open my inbox and find new papers arrived there. Some hopefully the majority — will be papers I have commissioned; others will fall into one of two broad categories:

- Academics in search of an outlet; or - Suppliers with a story to tell.

Of these, it is definitely the second category that causes the greatest heart searching. Unsolicited academic papers usually meet the journal's standards as far as writing goes. It is then just a question of determining whether they have anything relevant or interesting to say. As one referee recently responded to an author in another journal: "Are there any concrete recommendations falling out of this paper? Or is academic writing meant to be a bit fluffy?'

Not altogether fair, but there is a smidgeon of truth to it. Academics are writing for a particular community that holds impartiality in high regard. At times, that appears to translate as a reluctance to take a stand on anything. 
But it is the suppliers who are difficult. Some do understand the game: it is fine for them to write up case histories; to provide results and also comparisons that can subsequently be challenged. It is not alright to submit a paper that boils down to little more than 'we're the greatest!'. And that could be that except for two things. First, some of the most interesting developments in CRM originate with suppliers. Secondly, some of the even more interesting developments emerge from real partnerships between suppliers and their clients.

If one steps back a decade or so, there were academics writing sensibly about geodemographics: but these were few and far between. To debate the subject without input from CACI or CCN (now Experian) would have been pointless.

Equally, the boundaries between what is academic and what is commercial blur. Superprofiles emerged from a highly academic background: ACORN itself was a tool of government in the UK long before it went commercial. Many of the most recent developments in analytical tools, or data matching, or genetic algorithms start as somebody's $\mathrm{PhD}$ project - until they discover that quality academic thought actually commands a good market price.

All of which brings me back to the navel-gazing with which I started this editorial. There is the usual mix of papers: the take-up of e-services (Jon Chidley); a follow-up from Alan Tapp on media neutral planning; an interesting exploration of issues involved in aligning IT and marketing (Kai Wehmeyer); life-time value as the basis for profitability (Amoy Yang); and a return to the issue of e-mail and mixed mode database surveys (Roy \& Berger). In addition, there are the two data quality papers that fall into the practice paper. They reflect approaches taken by companies in this area to help organisations clean up their act internally. They appear to have had some success.

I think it is quite helpful for businesses to be able to read about such initiatives. A major part of the CRM story is how organisations ought now to be building partnerships, rather than treating suppliers with a 'them versus us' disdain.

Therefore I would like to publish more such supplier stories. Not all of them, by any means.

It is my intention that the journal should remain a serious academic enterprise - which means refereeing and a continuation of current standards. But I believe there is room for perhaps one paper per issue which is about claims (and informed exploration of those claims). So long as such papers are signposted as coming from an interested party, I think that the readers of Journal of Database Marketing are grown up enough to take them with the requisite pinch of salt and - furiously mixing my metaphors - to sift the chaff from the wheat.

At least, I think that's the case. But if any reader has views on this subject, please do not hesitate to make them known. I will read them with interest.

JOHN OZIMEK Editor 